\title{
Heart rate and cardiac output after atropine in anaesthetised infants and children
}

\author{
Georgina McAuliffe MB BS FRCA, \\ Bruno Bissonnette MD FRCPC, \\ Tiscar Cavallé-Garrido MD, * \\ Christine Boutin MD FRCPC*
}

Purpose: Heart rate is considered to be a major determinant of cardiac output in infants and small.children but the relationships between age, heart rate and cardiac output in humans have never been dearly established. This study was designed to determine the change in cardiac output following atropine $i v$ to anaesthetised infants and small children.

Methods: Following Institutional Ethics Committee approval and written-informed consent, 20 ASA I or II unpremedicated patients aged from I to 36 mo were studied. Anaesthesia was induced with $5 \mathrm{mg} \cdot \mathrm{kg}^{-1}$ thiopentone, $2 \mu \mathrm{gg}^{-1}$ fentanyl and maintained with halothane $0.5 \%$ in nitrous oxide $66 \%$ in oxygen. Vecuronium $0.1 \mathrm{mg} \cdot \mathrm{kg}^{-1}$ was used to provide muscular relaxation. Cardiac output was measured by non-invasive transthoracic blind continuous-wave Doppler echocardiography before and after the administration of $0.02 \mathrm{mg} \cdot \mathrm{kg}^{-1}$ atropine iv.

Results: Atropine increased both heart rate and cardiac index by $31.1 \pm 12.8 \%$ and $29.4 \pm 17.3 \%$ respectively $(P<0.05)$. The cardiac index before atropine was $5.1 \pm 1.2 \mathrm{~L} \cdot \mathrm{min}^{-1} \cdot \mathrm{m}^{-2}$ and the increase after atropine varied widely from 1.4 to $52.1 \%$. Although atropine did not alter the overall stroke index the recorded changes ranged from -20.8 to $+18: 0 \%$. There was no association between age and either cardiac index or \% change in cardiac index after atropine. However, there was a positive but weak correlation between percentage change in heart rate and cardiac output $\left(r^{2}=0.46\right)$.

Conclusion: Atropine causes a variable increase in cardiac output in infants and children aged between $I$ and $36 \mathrm{mo}$. The change in cardiac output, considering the limits of the transthoracic echocardiography methodology, suggests that this is related to the increase in heart rate but is not dependent of age.

Objectif : La fréquence cardiaque est considérée comme un déterminant majeur du débit cardiaque chez les nourissons et les jeunes enfants mais la relation entre l'âge, la fréquence et le débit n'a jamais été nettement établie chez l'humain. Cette étude visait à déterminer l'importance des variations du débit cardiaque après l'administration iv d'atropine chez des nourissons et des jeunes enfants sous anesthésie.

Méthodes : Après l'obtention de la sanction du comité d'éthique et d'un consentement éclairé par écrit, 20 patients ASA I et Il non préméđiqués âgés de un à 36 mois ont été recrutés pour cette étude. L'anesthésie était induite avec $5 \mathrm{mg} \cdot \mathrm{kg}^{-1}$ de thiopentone; $2 \mu \mathrm{g} \cdot \mathrm{kg}^{-1}$ de fentanyl et maintenue avec de l'halothane $0,5 \%$ dans du protoxyde d'azote $66 \%$ en oxygène. Le vécuronium $0,1 \mathrm{mg}^{\mathrm{kg}} \mathrm{g}^{-1}$ assurait le relâchement musculaire. Le débit cardiaque était mesuré par échocardiographie Doppler transthoracique à ondes continues avant et après l'administration de $0,02 \mathrm{mg} \cdot \mathrm{kg}^{-1}$ d'atropine iv.

Résultats : L'atropine a faít augmenter la fréquence et le débit cardiaque respectivement de $31,1 \pm 12,8 \%$ et $29,4 \pm 17,3 \%(P<0,05)$. Avant l'atropine, l'index cardiaque était de $5,1 \pm 1,2 \mathrm{~L} \cdot \mathrm{min}^{-1} \cdot \mathrm{m}^{-2}$ et son augmentation après atropine a varié largement entre 1,4 et $52,1 \%$. Bien que l'atropine riait pas modfifié l'index systolique dans l'ensemble, des extrèmes de l'ordre de $-20,8$ à + 18\% étaient enregistrés. Il n'y avait pas d'association entre l'âge et l'index cardiaque ou le pourcentage de changement de l'index cardiaque après l'atropine. Cependant, il existait une corrélation positive mais faible entre le pourcentage de changement pour la fréquence et le débit cardiaque $\left(r^{2}=0,46\right)$ :

Conclusion : L'atropine provoque une augmentation variable du débit cardiaque chez les nourrissons et les enfants âgés de un à 36 mois. Tout en tenant compte des limitations techniques de l'échócardiographie trànsthoracique, la variabilité du débit cardiaque suggère que l'augmentation est en rapport avec l'augmentation de la fréquence cardiaque mais qu'elle est indépendante de l'âge.

From the Departments of Anaesthesia and Cardiology, ${ }^{*}$ The Hospital for Sick Children, University of Toronto, Ontario, Canada, M5G 1X8. Dr. Cavalle-Garrido was funded by the Spanish Ministry of Health (Fondo de Investigation Sanitaria), Grant No. 94/5364.

Address correspondence to: Dr. B. Bissonnette.

Accepted for publication October 26, 1996. 
A POSITIVE inotropic effect has been demonstrated by increasing the frequency of myocardial contraction in excised myocardial strips, isolated hearts, and in in situ hearts of anaesthetised preparations. ${ }^{1-3}$ However, the physiological importance of this response in the intact human heart is uncertain and has been questioned by previous authors. ${ }^{4}$

It is thought that the myocardium in small children and particularly in neonates is less compliant than in adults and, as a result, develops greater wall tension when stretched. ${ }^{5}$ Thus, children are reported to be less able to increase their stroke volume than are adults and cardiac output regulation is believed to be predominantly heart rate dependent in younger age groups. 5,6

Atropine is an anticholinergic agent commonly used in paediatric anaesthesia to increase heart rate and prevent intra-operative episodes of bradycardia. It is not considered to have a direct inotropic effect. ${ }^{7}$ Invasive measurement of cardiac output is usually unsuitable for the investigation of normal healthy infants and children but recent advances in the use of ultrasonic techniques (continuous-wave Doppler echocardiography) have made the non-invasive estimation of cardiac output possible in paediatric subjects. ${ }^{8-10}$

This study was designed to evaluate the effect of $0.02 \mathrm{mg} \cdot \mathrm{kg}^{-1}$ atropine iv on cardiac output in anaesthetised infants and children and to determine the relationships between cardiac output, heart rate and age.

\section{Methods}

After obtaining approval from the Human Subject Review Committee and written-informed consent from the parents, 20 ASA I or II children aged from one to thirty-six months undergoing elective surgical procedures for which tracheal intubation was indicated were studied. Patients with cardiac and neurological disease or patients with any contraindication to the anaesthetic drugs utilised in the study were excluded.

The children were fasted and did not receive premedication. After arrival in the operating room an ECG, blood pressure cuff and pulse oximeter were applied. The insertion of a $24 \mathrm{G}$ iv cannula was facilitated by the administration of nitrous oxide $66 \%$ in oxygen by facemask. During the study heart rate and rhythm (lead II), $\mathrm{SpO}_{2}$ and $\mathrm{P}_{\mathrm{ET}} \mathrm{CO}_{2}$ were monitored continuously using a Macintosh computer (Apple Co., Cupertino, CA) and an on-line analogue-digital interface (Biolynx, Montreal, Canada). Blood pressure was monitored non-invasively prior to induction of anaesthesia and at two minute intervals thereafter.

Anaesthesia was induced with $5 \mathrm{mg} \cdot \mathrm{kg}^{-1}$ thiopentone and $2 \mu \mathrm{g} \cdot \mathrm{kg}^{-1}$ fentanyl. Vecuronium $0.1 \mathrm{mg} \cdot \mathrm{kg}^{-1}$ was administered to facilitate tracheal intubation. All drugs were administered by rapid bolus injection followed immediately by normal saline flush. Anaesthesia was maintained with halothane $0.5 \%$ end-tidal in nitrous oxide $66 \%$ in oxygen by manual intermittent positive pressure ventilation (IPPV). Oxygen saturation and $\mathrm{P}_{\mathrm{ET}} \mathrm{CO}_{2}$ were maintained within normal limits (>97\% and $35-45 \mathrm{mmHg}$ respectively) using the Jackson Rees modification of the Ayre's T-piece circuit. Tracheal intubation was performed $90 \mathrm{sec}$ after administration of vecuronium and mechanical IPPV was instituted.

Venous access was maintained by a slow infusion of lactated Ringers solution. Five minutes after tracheal intubation a baseline echocardiographic and Doppler study was performed by a cardiologist (TC) to determine cardiac output. A Hewlett-Packard Sonos 1500 (Hewlett-Packard, Andover, Massachusetts) equipped with 7.5-5.5, 3.5-2.7, 2-2.5 $\mathrm{MHz}$ transducers and 2 $\mathrm{MHz}$ continuous-wave non-image Doppler transducer was used. The aortic orifice diameter was obtained by $M$-mode, measuring from the trailing edge to the leading edge at the peak of the $T$ wave. Doppler spectral display of the flow across the aortic valve into the ascending aorta was measured by blind continuous-wave Doppler from the suprasternal notch window. This technique of echocardiographic measurement of the aortic root and determination of the blood flow has been demonstrated to provide the most reproducible results following serial measurements of $\mathrm{CO}$ in an infant by the same observer. ${ }^{8}$ The velocity-time integral of the waveform was obtained by planimetry. The ejection time was measured from the beginning to the end of the aortic flow tracing. Heart rate was obtained by simultaneous recording of the ECG All measurements were based on average data obtained from three consecutive beats. The cardiac output (V) was calculated from the product of stroke volume (SV) and heart rate. The stroke volume $\left(\mathrm{cm}^{3}\right)$ was calculated by multiplying the aortic valve area $\left(\mathrm{cm}^{2}\right)$ and the velocity-time integral $(\mathrm{cm})$. This technique has been previously validated in infants and small children..$^{11-13}$

After baseline cardiac output measurements were recorded $0.02 \mathrm{mg} \cdot \mathrm{kg}^{-1}$ atropine ip was administered followed by a normal saline flush. After $15 \mathrm{sec}$ steadystate of constant heart rate, a second echocardiographic estimation of cardiac output was obtained and the study period concluded.

\section{Statistical Analysis}

All data with parametric values are reported as mean \pm standard deviation. The sample size was calculated accepting an increase in cardiac output of $20 \%$ from baseline values of 2.6-3.2 $\pm 0.7 \mathrm{~L} \cdot \mathrm{min}^{-1} \cdot \mathrm{ml}^{-2}$ as representing 
a clinically relevant change. ${ }^{10}$ The power was 0.8 a $\alpha=0.05$. Parametric data before and after atropine $w$ compared using paired Student's t-tests. Associatic and coefficients of determination $\left(r^{2}\right)$ between card output, heart rate and age were determined using lin regression analysis. The reproducibility of the intrac server determination of Doppler measurements v determined from five $\mathrm{CO}$ estimates obtained for $e^{2}$ parient. The coefficient of variation was used. $P<0.05$ was accepted as statistically significant.

\section{Results}

Demographic data are summarised in Table $I$. Atropine increased heart rate and cardiac index $(P<0.05)$ (Table II). There was no alteration of stroke index although the change ranged from -20.8 to $+18.0 \%$. The $\%$ increase in cardiac index following atropine varied widely from 1.4 to $52.1 \%$.

The correlation between heart rate and cardiac index was poor both before $\left(\mathrm{r}^{2}=0.05, P=0.36\right)$ and after $\left(\mathrm{r}^{2}=0.00, P=0.99\right)$ the administration of atropine (Figure 1). The \% increase in cardiac index after atropine was unrelated to age $\left(P=0.89, \mathrm{r}^{2}=0.00\right)$ (Figure 2). Furthermore, there was no association between age and absolute cardiac index either before or after atropine. Although the \% change in heart rate correlated poorly with the \% change in cardiac index $\left(r^{2}=0.47\right)$, there was a positive association between these variables $(P<0.05)$ (Figure 3 ).

There were no complications throughout the study.

\section{Discussion}

This study demonstrated that $0.02 \mathrm{mg} \cdot \mathrm{kg}^{-1}$ atropine iv caused a variable increase in both heart rate and cardiac output in anaesthetised infants and children aged

TABLE I Demographic data

\begin{tabular}{ll}
\hline Age (months) & $16.0 \pm 11.0(1.0-36.0)$ \\
$01-12 \mathrm{~m}(\mathrm{n})$ & 9 \\
$13-36 \mathrm{~m}(\mathrm{n})$ & 11 \\
Weight $(\mathrm{kg})$ & $11.0 \pm 3.6(5.3-17.8)$ \\
Sex (M:F) & $12: 8$
\end{tabular}

Mean $\pm S D$ (range)

TABLE II The effect of atropine on heart rate, cardiac index and stroke index.

\begin{tabular}{llll}
\hline & Pre-atropine & Post-atropine & $* P<0.05$ \\
\hline Heart rate & $122 \pm 17$ & $158 \pm 15$ & $*$ \\
$\quad\left(\right.$ beats $\cdot$ min $\left.^{-1}\right)$ & $(102-138)$ & $(135-189)$ & \\
Cardiac index & $5.1 \pm 1.2$ & $6.5 \pm 1.4$ & $*$ \\
$\quad\left(\mathrm{~L} \cdot \mathrm{min}^{-1} \cdot \mathrm{m}^{-2}\right)$ & $(2.1-7.4)$ & $(2.7-8.6)$ & \\
Stroke index & $42.0 \pm 10.3$ & $41.3 \pm 9.8$ & NS \\
$\left(\mathrm{ml} \cdot \mathrm{m}^{-2}\right)$ & $(17.3-60.8)$ & $(17.7-57.9)$ & \\
\hline
\end{tabular}

Mean \pm SD (range)

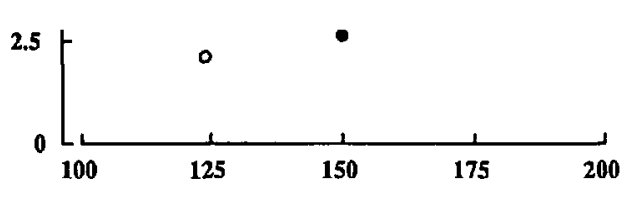

Heart Rate (beats'min ${ }^{-1}$ )

FIGURE 1 Relationship between heart rate and cardiac index before and after atropine.

${ }^{\circ}$ pre-atropine; - post-atropine.

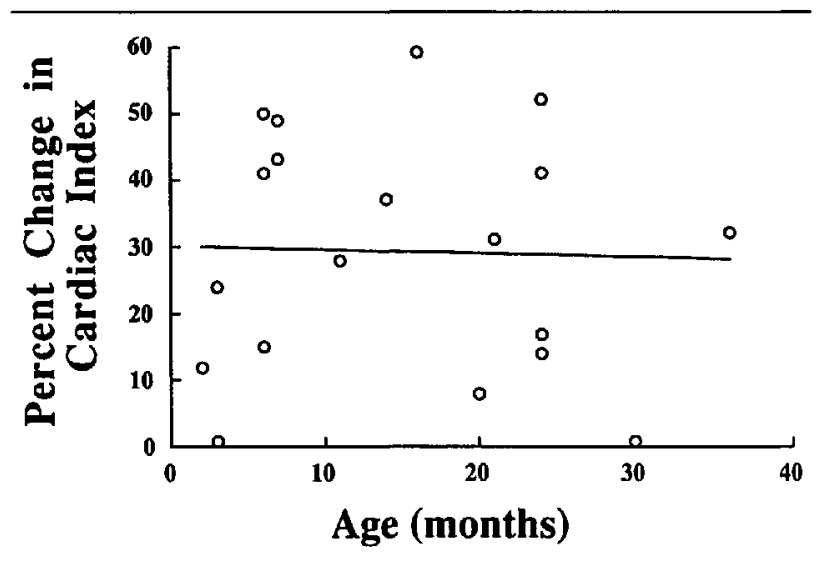

FIGURE 2 Relationship between age and \% change in cardiac index after atropine.

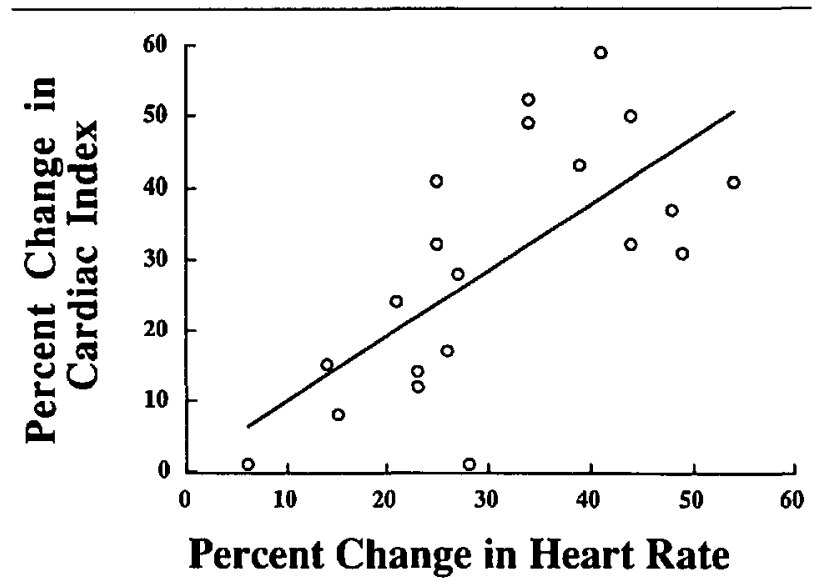

FIGURE 3 Relationship between $\%$ change in heart rate and \% change in cardiac index after atropine. 
from 1 to $36 \mathrm{mo}$. The magnitude of the increase in heart rate did not correlate well with the increase in cardiac output because atropine may have a variable effect on stroke volume, which is a determinant factor in the calculation of cardiac output. This suggests that, after atropine, the increase in heart rate decreases the ventricular filling time and the preload effects on cardiac output. There was no relationship between age and either cardiac output or the magnitude of cardiac output increase following administration of atropine. In addition, there was poor correlation between heart rate and cardiac output overall.

It is commonly assumed, in paediatric practice, that the increase in heart rate after atropine is likely due to an increase cardiac output (the product of stroke volume and heart rate). The data from this study suggests that this may be an over-simplification because atropine caused a wide range of effects on heart rate, stroke volume and cardiac output. Although atropine led to an increase in cardiac output in the infants and children studied, the range of this increase varied widely from 1 to $52 \%$. This confirms that 0.02 $\mathrm{mg} \cdot \mathrm{kg}^{-1}$ atropine produced the expected increase in $\mathrm{HR}$ but the magnitude of its effect on $\mathrm{CO}$ was variable among patients. This contention is supported by data suggesting that the increase in cardiac ouput appeared to be unrelated to age.

The belief that the cardiac output of neonates and infants is predominantly heart rate dependent has arisen from a variety of sources. Clinically, bradycardia in infants is associated with low cardiac output which implies that the immature heart has a limited ability to increase stroke volume compared with that of the adult. However, the influence of "normal" heart rates in determining cardiac output in infants and children has not been established. Much of the relevant information on this subject has been extrapolated from animal models.

Rudolph $e t a l .{ }^{12}$ studied the effects of spontaneous and induced changes of heart rate on cardiac output in 23 lambs in utero. They reported that spontaneous changes in heart rate were associated with concurrent changes in right and left ventricular outputs with a linear relationship between rate and output. However, the use of right atrial pacing in five animals increased the output of both ventricles whereas left atrial pacing increased only right ventricular output. Vagal stimulation resulted in decreases in heart rate and cardiac output. Extrapolation of these data to human infant physiology remains limited since surgery was required to place appropriate monitoring devices. Post-operative haemodynamics have been shown to change considerably in the recovery period with increases in left ventricular output of up to $100 \%$ occuring over the first 10 days. ${ }^{13}$

Kirkpatrick et $a l^{13}$ studied seven foetal lambs two weeks after surgical instrumentation. They failed to show changes in left ventricular output during wide variations in spontaneous heart rate. Although the Frank-Starling relationship remained intact, refuting evidence that stroke volume has little importance in the regulation of cardiac output compared with the role of changing heart rate, they concluded that there was no evidence that heart rate is the primary determinant of cardiac output.

Winberg et al. ${ }^{10}$ reached similar conclusions after studying the cardiac output of 16 healthy term infants using echocardiography. They demonstrated a poor association between heart rate and left ventricular output and suggested that stroke volume and not $\mathrm{HR}$ was the main determinant of neonatal left ventricular output.

The cardiac indices measured before the administration of atropine in this study appeared high with a mean of $5.1 \mathrm{~L} \cdot \mathrm{min}^{-1} \mathrm{~m}^{-2}$. Data utilising Doppler echocardiography in unsedated infants and children reported resting cardiac output between 2.6 and 3.2 $\mathrm{L} \cdot \mathrm{min}^{-1} \mathrm{~m}^{-2}{ }^{11}$ However, another study of 10 sedated children without intracardiac shunts or lesions reported $\mathrm{CO}$, obtained by Doppler echocardiography, up to $5.5 \mathrm{~L} \cdot \mathrm{min}^{-1} \mathrm{~m}^{-2} \cdot{ }^{14}$ It could speculated that high circulating catecholamine levels, resulting from separation of unpremedicated children from their parents, was the cause of this high CO. Furthermore, one may postulate that the children were in a relatively light plane of anaesthesia during tracheal intubation triggering a sympathetic response that was still present five minutes later. On the other hand, administration of myocardial depressant anaesthetic agents such as halothane and thiopentone could have contributed to the reduction of $\mathrm{CO} .{ }^{15}$ Either speculation was not supported by the heart rates recorded at the time of the first cardiac output estimation. The suggestion that the increase in $\mathrm{CO}$ is related to peripheral vasodilatation after induction of anaesthesia may be most appropriate. Thiopentone may reduce systemic vascular resistance, promoting an increase in blood flow if contractility and blood pressure remain relarively unaffected. Mellander et al. reported an increased $\mathrm{CO}$ following injection of chlorpromazine, meperidine or promethazine in their children, supporting the concept of peripheral vasodilatation. ${ }^{14}$ Normal cardiac output responses of healthy unpremedicated infants and children to this technique of induction and maintenance of anaesthesia have never been described so it may be that the seemingly high $\mathrm{CO}$ values are normal. The inability to obtain reliable awake pre-induction 
measurements in these infants made interpretation of these high cardiac indices difficult.

There are a number of methodological considerations in this study which warrant further discussion. The measurement of cardiac output by Doppler echocardiography is subject to several possible sources of error. ${ }^{8,16}$ Motion artefacts may result in inaccurate measurements. However, this was minimised by studying patients who were anaesthetised and paralysed. The angle of insonation of the Doppler beam must be maintained $<30^{\circ}$ to the axis of aortic blood flow to prevent underestimation of aortic flow velocity. The suprasternal approach used in this study ensured that the angle of insonation was between 0 and $15^{\circ}$ with the result that the cosine function of the angled used in the calculation of the blood flow velocity and the estimated error was as small as possible. ${ }^{14}$ Furthermore, the magnitude of this problem was minimised by using a continuous wave $2 \mathrm{MHz}$ transducer of smaller size than a pulse-gated Doppler probe. This frequency permits optimal alignment of the ultrasound beam and the longitudinal axis of the ascending aorta. Mellander $e t$ al. demonstrated that cardiac output can be accurately measured noninvasively in infants and children by combined continuous wave Doppler and $\mathrm{M}$-mode echocardiography. ${ }^{14}$

The accurate measurement of aortic diameter is vital for the calculation of cardiac output. It represents an important limitation because the linear measurement obtained (radius) is squared to calculate the cross-sectional area of the aorta (circumference). This provides a large potential source of crror since the error will also be squared if the original diameter is slightly inaccurate. ${ }^{17}$ Aortic diameter was obtained by $\mathrm{M}$-mode technology, measured from tailing to leading edge (internal diameter) at the peak of the $T$ wave. This technique is the most appropriate for calculation of volumetric flow in infants and children. The mean of five heartbeats was used. While it is the most basic mode of recording in transthoracic echocardiography, it remains the most useful for the precise timing of events within the cardiac cycle and more subtle change in motion or dimension can be appreciated. It has been previously demontrated that this technique allows duplication of serial CO measurements in infants when made by the same observer. ${ }^{18}$ Intraobserver Doppler aortic flow velocity measurements made from the suprasternal notch are most reproducible and repeatable when obtained by a single observer. ${ }^{18}$ The within-observer variability was only $18 \%$ of the total variability in a single measurement whereas between observer variability contributed to increase three fold the calculation error of the data reported. ${ }^{19}$ The mean coefficient of variation for mean velocity measurements in this study was $5.1 \%$. The estimated standard deviation caused by the observer in this study corresponded to $6.3 \%$ of the total study variance while using continuous Doppler flow determination. In fact, it is suggested that differences $>13 \%$ in variable measurements reflect true changes between two examinations recorded while analysed by the same person. ${ }^{20}$ Overestimation of the aortic diameter is still very possible. The calculation of the aortic valve area is obtained from the square of the aortic diameter. Therefore, as previously indicated, small errors in this measurement cause large errors in $\mathrm{CO}$ estimates. The cardiac cycle timing used to measure the diameter may have also vary between patients. Systolic aortic diameter was used in this study which is reported in adults to be $11 \%$ greater than the diastolic diameter. If this occurs it could have led to consistent overestimation of aortic flow. ${ }^{21}$

Finally, small infants and children have faster HRs and smaller anatomical structures than their adult counterparts. Assumption of flat velocity profile over most of the cross-sectional area may contribute to this error. The mean velocity in the sample volume is equivalent to the mean velocity over the entire cross section in a vessel with a flat velocity profile or simply if the sample volume covers the entire cross section of this vessel. However, because the velocity profile of the aortic root is normally not absolutely flat, it causes the sample volume diameter to be smaller than the aortic root diameter. ${ }^{18}$ Therefore, the measurement of mean velocity will depend on the shape of the velocity profile and its location in the aortic root. Thus, true velocity corresponds to the central core of the peak velocity profile measured. The measurement obtained will usually be representative of a laminar flow pattern which is known to approximate better the mean velocity of the entire flow and, consequently, the mean arterial blood flow. In this study, because a $2 \mathrm{MHz}$ probe was used, the ability to measure the central axis of the aortic root flow velocity profile was improved because the width (sample volume of the insonating beam) was smaller.

Variation between different observers was eliminated by allowing only one experienced cardiologist to perform all the studies. It is appropriate to speculate that measurement obtained by two different observers after the administration of atropine for each patient would have added a time-dependant factor between continuous-wave Doppler examinations. In a study of 10 children, it was demonstrated that the difference in the results obtained between two experienced observers was probably not related to systematic differences in the examination or measurement techniques but rather, by an actual change in cardiac 
performance. ${ }^{21}$ They suggested that the difference observed was related to the time between the examinations.

In summary, administration of ip atropine increased cardiac output in anaesthetised infants and children aged from 1 to $36 \mathrm{mo}$. However, the magnitude of the increase varied considerably from 1 to $56 \%$. There was a positive but weak ( $46 \%$ ) association between heart rate and cardiac output. Neither the cardiac indices obtained before or after the administration of atropine nor the \% change in cardiac output that followed atropine administration were associated with age. These observations suggest, within the limit of methodology used, that while heart rate contributed to the increased in cardiac output it was probably not the sole determinant of aortic blood flow in this age group.

\section{Acknowledgement}

The authors would like to thank Dr. J. E. S. Relton for his help in the preparation of the manuscript.

\section{References}

1 Dale AS. The staircase phenomenon in ventricular muscle. J Physiol 1932; 75: 1-16.

2 Monroe RG, French GN. Left ventricular pressurevolume relationships and myocardial oxygen consumption in the isolated heart. Circ Res 1961; 9: 362-74.

3 Lendrum B, Feinberg H, Boyd E, Katz LN. Rhythm effects on contractility of the beating isovolumic left ventricle. Am J Physiol 1960; 199: 1115-20.

4 Higgins $C B$, Vatner SF, Franklin D, Braunwald $E$. Extent of regulation of the heart's contractile state in the conscious dog by alteration in the frequency of contraction. J Clin Invest 1973; 52: 1187-94.

5 Greeley WJ, Kern FH. Anesthesia for pediatric cardiac surgery. In: Miller RD (Ed.). Anesthesia, 4th ed. New York: Churchhill Livingstone Inc., 1994; 1811-4.

6 Strafford $M A$. Cardiovascular physiology. In: Motoyama EK, Davis PJ (Eds.). Smith's Anesthesia for Infants and Children, 6th ed. St. Louis: C V Mosby Co., 1996; 76-81.

7 Brown JH, Taylor P. Muscarinic receptor agonists and antagonists. In: Goodman LS, Gillman A (Eds.). The Pharmacological Basis of Therapeutics, 9th ed. New York: McGraw-Hill, 1996; 149-53.

8 Alverson DC, Eldridge $M$, Dillon $T$, Yabek SM, Berman $W$. Noninvasive pulsed Doppler determination of cardiac output in neonates and children. J Pediatrics 1982; 101 : 46-50.

9 Nishimura RA, Callaban MJ, Schaff HV, Ilstrup DM, Miller FA, Tajik AJ. Noninvasive measurement of cardiac output by continuous-wave Doppler echocardiog raphy: initial experience and review of the litterature. Mayo Clin Proc 1984; 59: 484-9.

10 Winberg $P$, Lundell, $B P W$. Left ventricular stroke volume and output in healthy term infants. American Journal of Perinatology 1990; 7: 223-6.

11 Sholler GF, Celermajer JM, Whight CM, Bauman AE. Echo Doppler assessment of cardiac output and its relation to growth in normal infants. Am J Cardiol 1987; 60: 1112-6.

12 Rudolph $A M$, Heymann MA. Cardiac output in the fetal lamb: the effects of spontaneous and induced changes of heart rate on right and left ventricular output. Am J Obset Gynecol 1976; 124: 183-92.

13 Kirkpatrick SE, Pitlick PT, Naliboff J, Friedman WF. Frank-Starling relationship as an important determinant of fetal cardiac output. Am J Physiol 1976; 231 : 495-500.

14 Mellander M, Sabel K-G, Caidabl K, Solymar L, Eriksson B. Doppler determination of cardiac output in infants and children: comparison with simultaneous thermodilution. Pediatr Cardiol 1987; 8: 241-6.

15 Barash PG, Glanz S, Katz JD, Taunt K, Talner NS. Ventricular function in children during halothane anesthesia: an echocardiographic evaluation. Anesthesiology 1978; 49: 79-85.

16 Hatle L. Assessment of aortic blood flow velocities with continuous wave Doppler ultrasound in the neonate and young child. J Am Coll Cardiol 1985; 5: 113S-9.

17 Inblen $H$, Amilie JP, Dale J, et al. Determination of cardiac output by Doppler echocardiography. Br Heart J 1984; 51: 54-60.

18 Hudson $I$, Houston A, Aitchison T, Holland B, Turner $T$. Reproducibility of measurements of cardiac output in newborn infants by Doppler ultrasound. Arch Dis Child 1990; 65: 15-9.

19 Gardin JM, Dabestani A, Matin K, Allfie A, Russell D, Henry WL. Reproducibility of Doppler aortic blood flow measurements: studies on intraobserver, interobserver and day-to-day variability in normal subjects. Am J Cardiol 1984; 54: 1092-8.

20 Hanseus $K$, Björkhem $G$, Lundström $N-R$. Cardiac function in healthy infants and children: Doppler echocradiography evaluation. Pediatr Cardiol 1994; 15: 211-8.

21 Greenfield JC, Patel DJ. Relation between pressure and diameter in the ascending aortal of man. Circ Res 1962; 10: 778-81. 